\title{
钒酸铋光电催化分解水的研究进展
}

\author{
叶凯航 ${ }^{1,2}$, 汤桐釒金 ${ }^{1}$ 梁志庭 ${ }^{1}$, 纪红兵 ${ }^{1,3}$, 林展 $^{1^{*}}$, 杨世和 ${ }^{2 *}$ \\ 1. 广东工业大学轻工化工学院, 广州市清洁交通能源化学重点实验室, 广州 510006; \\ 2. 北京大学深圳研究生院化学生物学与生物技术学院, 广东省纳米微米材料研究重点实验室, 深圳 518055; \\ 3. 中山大学化学学院, 精细化工研究院, 广州 510275 \\ * 联系人, E-mail: zhanlin@gdut.edu.cn; chsyang@pku.edu.cn
}

2021-03-04 收稿, 2021-06-03 修回, 2021-06-11 接受, 2021-06-15 网络版发表

国家自然科学基金(21972006)和中国博士后科学基金(2020M682616)资助

摘要 光电化学(photoelectrochemical, PEC)催化分解水制氢被认为是生态友好、规模化和可持续性地转化与储存 太阳能的理想途径之一, 但光阳极较低的工作效率限制了PEC分解水的发展. 近年来, 钒酸铋光阳极因具有较高的 理论光电流密度受到科学界的广泛关注. 大量的工作聚焦在如何将钒酸铋光阳极所具有的理论潜力尽可能地发挥 并应用至PEC分解水制氢. 本文通过回顾和分析钒酸铋光阳极的吸光效率、光生载流子分离效率与表面催化产氧 效率3个方面的研究进展, 对高性能钒酸铋光阳极的设计思路与合成方法进行评述、总结与展望, 为进一步挖掘钒 酸铋光电极的潜力与开发下一代光电极提供参考和思路.

关键词光电催化, 分解水, 钥酸铋, 光阳极

太阳能作为一种“零碳能源”有望解决人类社会发 展面临的能源与环境问题，而如何将太阳能转化为可 被人类利用且易于储存的燃料是其中的关键挑战 ${ }^{[1,2]}$. 因氢能具有环境友好、热值高、无毒等优势，太阳能 分解水制氢是实现“液态阳光”能源转化与储存计划最 为理想的途径之一 ${ }^{[1 \sim 4]}$. 光电化学 (photoelectrochemical, PEC)分解水作为“第三代太阳能技术”在近年来受到全 球广泛关注 ${ }^{[1-4]}$. PEC分解水反应器制氢是研究光电化 学催化科学问题的平台, 其工作效率主要由光电极的 性能决定 ${ }^{[5,6]}$. 因此，设计和制备环境友好、高活性、 低成本和高稳定性的可持续性光电极材料, 并将其应 用于PEC分解水制氢领域，具有重要的科学意义、应 用价值和社会效益.

光电极材料主要分为 $\mathrm{n}$ 型半导体的光阳极材料和 $\mathrm{p}$ 型半导体的光阴极材料 ${ }^{[1]}$. 其中, 单斜相的钒酸铋 $\left(\mathrm{BiVO}_{4}\right)$ 作为 $\mathrm{n}$ 型半导体, 可组成光阳极型PEC分解水反 应器(图1(a) $)^{[7,8]}$. 相较于光阴极材料, 由于光阳极的产 氧反应(oxygen evolution reaction, OER)是4电子反应 $\left(4 \mathrm{OH}^{-}-4 \mathrm{e}^{-}=2 \mathrm{H}_{2} \mathrm{O}+\mathrm{O}_{2} \uparrow\right)$, 其在反应动力学上更具挑 战性, 成为制约PEC分解水性能的主要因素 ${ }^{[9,10]} . \mathrm{BiVO}_{4}$ 作为一种极具前景的光电极材料, 因其带隙约为 $2.4 \mathrm{eV}$, 光响应波长范围为 $300 \sim 520 \mathrm{~nm}$, 相较于 $\mathrm{TiO}_{2}$ 与 $\mathrm{ZnO}$, 可吸收与利用更多的可见光并具有高达 $7.5 \mathrm{~mA} \mathrm{~cm}^{-2}$ 的理论光电流密度 ${ }^{[11,12]}$. 另外, 由于 $\mathrm{BiVO}_{4}$ 的导带位置 接近于 $0 \mathrm{~V}$ vs. NHE(normal hydrogen electrode), 相较于 赤铁矿型氧化铁(约 $0.6 \mathrm{~V}$ vs. NHE), $\mathrm{BiVO}_{4}$ 的导带更接 近于 $\mathrm{H}_{2}$ 的还原电位 ${ }^{[13,14]}$. 同时, 由于 $\mathrm{BiVO}_{4}$ 的价带接近 $2.5 \mathrm{~V}$ vs. NHE, 其作为阳极具有较强的催化产氧能 力 $^{[2]}$. 但是, 由于未经过改性修饰的 $\mathrm{BiVO}_{4}$ 存在吸光能 力较弱、光生载流子分离与传输性能差、表面催化产 氧动力学差等问题, $\mathrm{BiVO}_{4}$ 光阳极的性能一直达不到其 所具有的理论潜力 ${ }^{[15]}$. 近年来, 由于经过改性后的 
$\mathrm{BiVO}_{4}$ 具有较强的光生载流子传输能力与良好的稳定 性, 其作为可持续性PEC光电催化电极材料的典型引起 了科学界的极大关注 ${ }^{[15 ~ 17]}$. 为了更直观地研究 $\mathrm{BiVO}_{4}$ 作 为光阳极进行PEC分解水的过程, 本文将对其催化机制 涉及的各个步骤进行简要的阐述.

如图1(b)所示, $\mathrm{BiVO}_{4}$ 光阳极的工作机理主要分为 5步：(1) 光被 $\mathrm{BiVO}_{4}$ 光阳极捕获; (2) 产生电子与空穴 对; (3) 光生电子通过 $\mathrm{BiVO}_{4}$ 的导带传输至阴极进行析 氢反应; (4) 光生空穴通过价带传输至 $\mathrm{BiVO}_{4}$ 表面, 与 $\mathrm{OH}^{-}$进行析氧反应; (5) 光生电子与空穴在传输过程中 的重新复合. 光电极的光电流密度 $\left(J_{\mathrm{PEC}}\right)$ 是反映光电极 分解水性能的重要指标, 由其材料本身的理论最大光 电流密度 $\left(J_{\max }\right)$ 、光捕获效率(light harvesting efficiency, LHE)、光生载流子分离效率 $\left(\Phi_{\mathrm{Sep}}\right)$ 与催化产氧效率 $\left(\Phi_{\mathrm{OX}}\right)$ 所决定 ${ }^{[13]}$, 具体表达式如下:

$J_{\mathrm{PEC}}=J_{\text {max }} \times \mathrm{LHE} \times \Phi_{\text {Sep }} \times \Phi_{\mathrm{OX}}$.

而单电极的能量效率ABPE(applied bias photon-to-current efficiency)不仅要考虑电流密度, 还要考虑外加偏 压, 具体可表达为 ${ }^{[18-20]}$ :

$\mathrm{ABPE}=J_{\mathrm{PEC}} \times\left(1.23-V_{\text {bias }}\right) / P_{\text {light }} \times 100 \%$,

其中, $V_{\text {bias }}$ 对应光电极工作所加的偏压, $P_{\text {light }}$ 为光源的

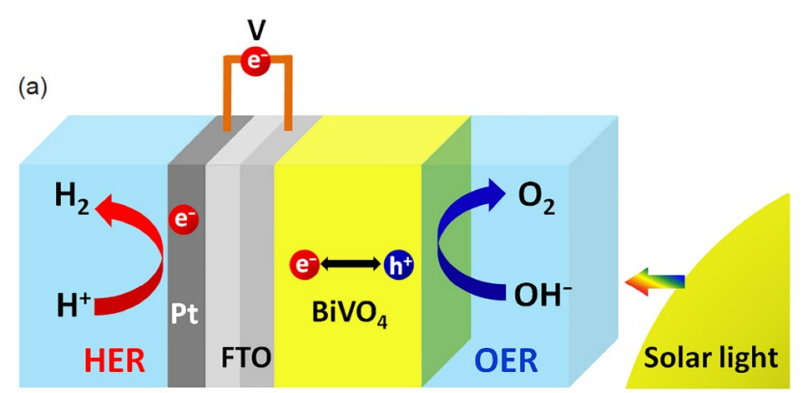

(b)

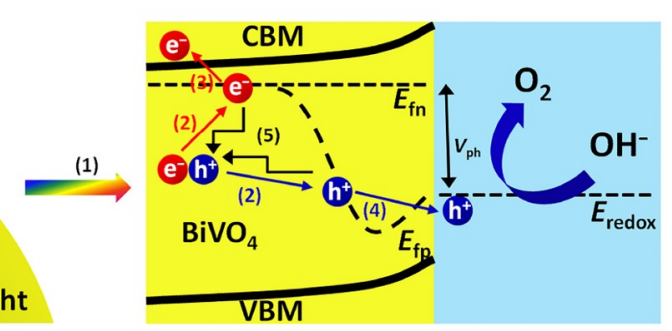

图 1 (网络版彩色) $\mathrm{BiVO}_{4}$ 光阳极型PEC分解水器件示意图 (a) 和 $\mathrm{BiVO}_{4}$ 光阳极工作机制示意图(b)

Figure 1 (Color online) Schematic diagram of the $\mathrm{BiVO}_{4}$ photoanode based PEC water splitting cell (a) and schematic diagram illustrating the working mechanism of $\mathrm{BiVO}_{4}$ photoanode (b)
功率. 因此, 虽然 $\mathrm{BiVO}_{4}$ 的 $J_{\max }\left(7.5 \mathrm{~mA} \mathrm{~cm}{ }^{-2}\right)$ 在常见的 可持续性光电极中尚属可观，但LHE、 $\Phi_{\mathrm{Sep}} 、 \Phi_{\mathrm{OX}}$ 、起 始电位与填充因子都是制约 $\mathrm{BiVO}_{4}$ 总体光催化性能的 重要因素 ${ }^{[21]}$. 如何降低载流子复合、优化界面能级匹 配以及减小过电位和能量损失是 $\mathrm{BiVO}_{4}$ 光阳极发展的 重要方向 ${ }^{[22,23]}$. 近年来, 这些方面有了很大的进展, 如 通过陷光结构或碳量子点(carbon quantum dots, CQDs) 增强 $\mathrm{BiVO}_{4}$ 吸光能力与光响应范围从而增加其 $J_{\max }$ 或

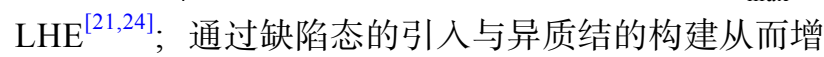
强其 $\Phi_{\mathrm{Sep}}{ }^{[25,26]}$; 通过引人助催化剂或对电极表面处理从 而增强 $\Phi_{\mathrm{OX}}{ }^{[27,28]}$. 本文侧重在提升 $\mathrm{BiVO}_{4}$ 吸光能力、光 生载流子分离能力与表面催化能力等方面的近期进展, 在此基础上简要归纳 $\mathrm{BiVO}_{4}$ 光阳极的设计思路及推广 的可能, 最后展望 $\mathrm{BiVO}_{4}$ 及其下一代光阳极的发展 趋势.

\section{1 吸光效率}

$\mathrm{BiVO}_{4}$ 的禁带宽度约为 $2.4 \mathrm{eV}$ ，因能可观地吸收利 用300 530 nm 的太阳光而获得科学界广泛关注 ${ }^{[29,30]}$. 如图2所示, 在模拟地球表面大气质量 $1.5 \mathrm{G}$ 的太阳光谱 (air mass 1.5 global solar spectrum, AM $1.5 \mathrm{G}$ )内, 所有光 子 $100 \%$ 地转化为电子后的电流密度约为 $26.3 \mathrm{~mA} \mathrm{~cm}^{-2}$, 而 $\mathrm{BiVO}_{4}$ 的光吸收只能覆盖波长小于 $530 \mathrm{~nm}$ 的太阳 光 ${ }^{[21]}$. 因此, 在 $\mathrm{AM} 1.5 \mathrm{G}$ 太阳光的照射下, $J_{\text {max }}$ 被限制在 $7.5 \mathrm{~mA} \mathrm{~cm}^{-2[11,12]}$. 同时, 由于实际制备出的光电极往往 存在一定的透光与反射, 限制了其LHE，导致 $\mathrm{BiVO}_{4}$ 在 实际吸光后所能达到的理论最大光电流密度 $\left(J_{\mathrm{abs}}=J_{\text {max }} \times\right.$ LHE)被限制在约 $4.5 \mathrm{~mA} \mathrm{~cm}^{-2[13,21]}$, 具体可表达为

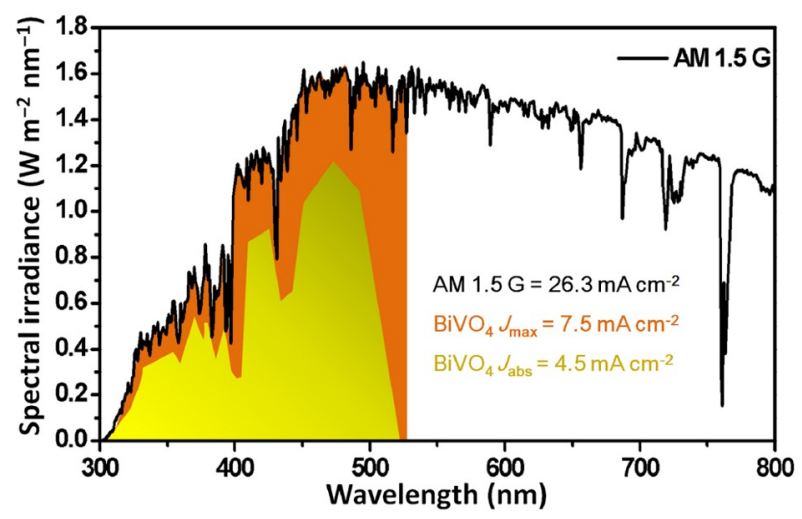

图 2 (网络版彩色)地球表面大气质量1.5 G(AM 1.5 G)太阳光谱下, 全部可转化的光电流密度与 $\mathrm{BiVO}_{4}$ 的 $J_{\max }$ 和 $J_{\mathrm{abs}}\left(J_{\mathrm{abs}}=J_{\max } \times \mathrm{LHE}\right)$ Figure 2 (Color online) Fully converted photocurrent density, $J_{\max }$ and $J_{\text {abs }}\left(J_{\text {abs }}=J_{\max } \times\right.$ LHE) of $\mathrm{BiVO}_{4}$ under air mass 1.5 global (AM 1.5 G) solar spectrum 
$J_{\mathrm{abs}}=\frac{e}{h c} \int_{0}^{\lambda_{0}} \lambda I_{\lambda}\left(1-10^{-A}\right) \mathrm{d} \lambda$,

其中, $I_{\lambda}$ 为太阳辐照度 $\left(\mathrm{W} \mathrm{m}^{-2} \mathrm{~nm}^{-1}\right), e$ 为电荷量, $h$ 为普朗克 常数, $c$ 为光速, $A$ 为吸光度(通过紫外-可见漫反射光谱对光 电极实际测得), 且 $1-10^{-A}$ 为光电极在特定波长下的LHE.

因此，提升 $\mathrm{BiVO}_{4}$ 吸光能力，即减少电极透光率与 反射率以提升LHE及拓宽吸光范围从而提升光电极的 $J_{\text {abs }}$, 是提升 $\mathrm{BiVO}_{4}$ 光阳极性能的直接手段. 本节将通过 缺陷调节、异质结构建以及陷光结构的设计合成 3 个 方面, 扼要总结 $\mathrm{BiVO}_{4}$ 光阳极吸光能力的提升策略.

\section{1 通过缺陷调节增强吸光能力}

由式(1)和(3)可知, $\mathrm{BiVO}_{4}$ 的 $J_{\text {max }}$ 由其禁带宽度所决 定，即拥有较小的禁带宽度理论上能获得更大的 $J_{\text {max }}$. 在 $\mathrm{BiVO}_{4}$ 中引人掺杂或空位的缺陷，是调节 $\mathrm{BiVO}_{4}$ 禁带 宽度的主要手段. Wang等人 ${ }^{[31}$ 将已制备好的 $\mathrm{BiVO}_{4}$ 在 氢气气氛下退火, 形成了具有氧空位缺陷的 $\mathrm{BiVO}_{4}$ 光阳 极，其禁带宽度减小，颜色变深. 这些氧空位缺陷的引
人不仅增加了吸光能力, 还提高了电荷传输能力, 从而 提升了其光电流密度 ${ }^{[31]}$. Tian等人 ${ }^{[32]}$ 通过氢等离子体 还原作用制备出了一种带有氧空位缺陷的黑色 $\mathrm{BiVO}_{4}$ 光阳极, 极大地增强了光阳极的吸光能力(禁带宽度减小 $0.3 \mathrm{eV}$ ). 通过负载无定型的 $\mathrm{TiO}_{2-x}$, 最终该电极在 $1.23 \mathrm{~V}$ vs. RHE的偏压下，可获得约 $6 \mathrm{~mA} \mathrm{~cm}^{-2}$ 的光电流密度. 另 外, $\mathrm{Kim}$ 等人 ${ }^{[33]}$ 将钒酸铋电极在氮气气氛下进行退火, 合成出具有氮掺杂缺陷与氧空位缺陷的 $\mathrm{BiVO}_{4}$ 光阳极. 通过理论计算与实验，证明了其禁带宽度的缩小与吸 光能力的增强是由氧空位缺陷与氮掺杂缺陷所导致的 (图3(a)). 人射光电转化效率(monochromatic incident photon-to-electron conversion efficiency, IPCE)红移更 是为吸光能力的增强使光电极性能提升提供了直接证 据 ${ }^{[33]}$. 因此，通过调节缺陷态改变 $\mathrm{BiVO}_{4}$ 的禁带宽度是 提升 $\mathrm{BiVO}_{4}$ 吸光能力从而提升其性能的主要手段之一.

\section{2 通过构建异质结提升吸光能力}

为了进一步拓宽 $\mathrm{BiVO}_{4}$ 的光响应范围, 通过引人禁

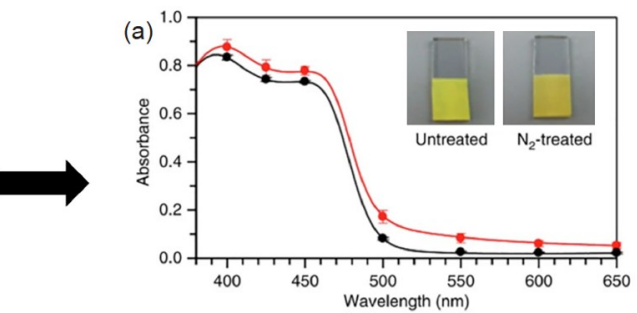

FTO
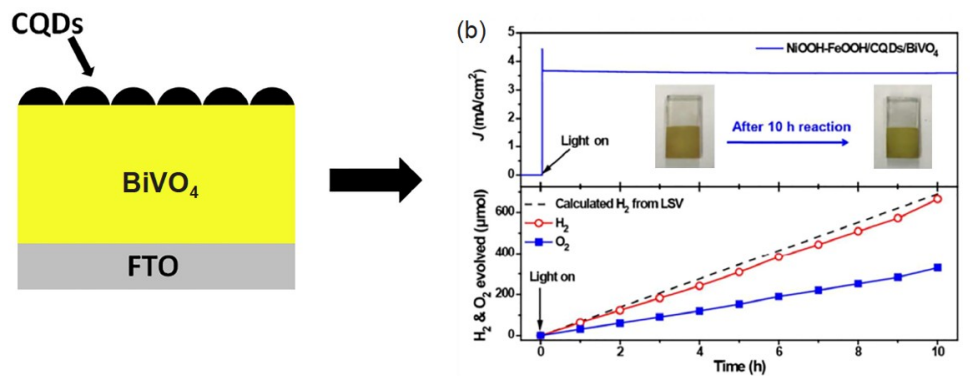

(c)

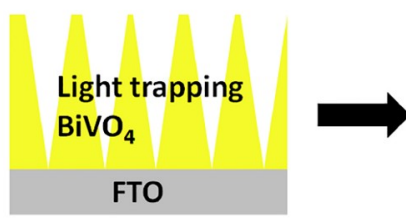

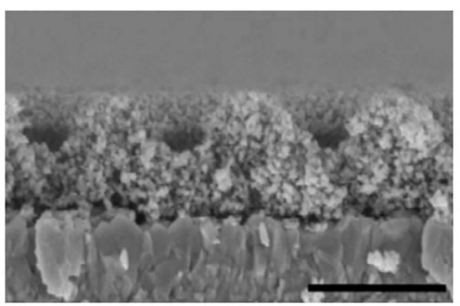

图 3 (网络版彩色) 3 种提升 $\mathrm{BiVO}_{4}$ 光阳极吸光能力的手段. (a) 氮气退火引入缺陷态 ${ }^{[33]}$; (b) 负载碳量子点组成异质结 ${ }^{[21]}$; (c) 构建陷光结构降低 光反射 ${ }^{[39]}$

Figure 3 (Color online) Three methods to improve the light absorption ability of $\mathrm{BiVO}_{4}$ photoanode. (a) Introduction of defect states by annealing in nitrogen $^{[33]}$; (b) loading of carbon quantum dots to form heterojunctions ${ }^{[21]}$; (c) construction of light trapping structures to reduce light reflection ${ }^{[39]}$ 
带宽度更窄、吸光能力更强的半导体材料与 $\mathrm{BiVO}_{4}$ 复 合形成异质结, 是另一种提升 $\mathrm{BiVO}_{4}$ 光阳极吸光能力 的重要手段. Tang等人 ${ }^{[34]}$ 与 $N a n$ 等人 ${ }^{[35]}$ 利用具有优异 吸光能力与电荷传输能力的CQDs与 $\mathrm{BiVO}_{4}$ 复合形成光 阳极. 因CQDs的引人，在与 $\mathrm{BiVO}_{4}$ 光阳极复合之后, CQDs吸光能力的优势很好地拓宽了光阳极的光响应 范围, 使复合光电极性能获得较大提升 ${ }^{[35]}$. 在此基础上, $\mathrm{Ye}$ 等人 ${ }^{[21]}$ 对 $\mathrm{CQDs} / \mathrm{BiVO}_{4}$ 光阳极体系进行了细致的研 究, 发现CQDs虽然能大幅提升光阳极的光响应范围, 但是由于CQDs本身催化产氧性能较弱, 其潜力并没有 得到尽可能的发挥. 据此, 我们在 $\mathrm{CQDs} / \mathrm{BiVO}_{4}$ 光阳极 中巧妙地结合羟基氧化铁与羟基氧化镍双层电催化剂 $(\mathrm{NiOOH} / \mathrm{FeOOH})$, 在 $1.23 \mathrm{~V}$ vs. RHE下取得了 $5.99 \mathrm{~mA} \mathrm{~cm}{ }^{-2}$ 的光电流密度, 且IPCE在300 800 nm波 段内均有一定的光电转化能力 ${ }^{[21]}$. 同时, 该电催化剂层 的保护作用极大地增强了 $\mathrm{CQDs} / \mathrm{BiVO}_{4}$ 光阳极的稳定 性(图3(b)). 因此, 除吸光效率外, 通过引人吸光能力更 强的材料与 $\mathrm{BiVO}_{4}$ 构建异质结光阳极时, 还需考虑是否 对光阳极的其他效率产生影响(如电荷分离效率、催 化产氧效率等).

\section{3 通过设计合成具有陷光结构的形貌提升吸光 能力}

由图2可知, 由于 $L H E$ 的限制, 虽然 $\mathrm{BiVO}_{4}$ 的理论电 流密度高达 $7.5 \mathrm{~mA} \mathrm{~cm}^{-2}$, 但因实际电极制备过程需要 考虑透光与反射等问题, 实际制备出的 $\mathrm{BiVO}_{4}$ 光阳极往 往只能拥有约 $4.5 \mathrm{~mA} \mathrm{~cm}{ }^{-2}$ 的光电流密度. 因此, 在制备

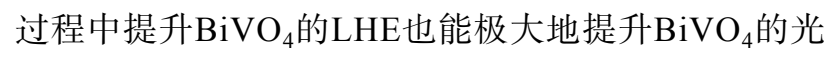
电流密度. 除了通过双电极堆叠从而进一步提升PEC器 件的整体LHE之外 ${ }^{[18]}$, 合成具有陷光结构的纳米形貌 同样是提升光电极LHE的有力手段. 陷光结构是通过 特定的形貌设计改进光电极的吸光能力, 从而极大地 提升光电极的性能 ${ }^{[24,36 ~ 39]}$. Qiu等人 ${ }^{[24]}$ 通过对掺杂氟的 二氧化锡(fluorine-doped tin oxide, FTO)导电玻璃基底 进行特别处理, 合成具有陷光结构的反向雉形纳米阵 列结构. 该结构被用作光电极基底, 从而降低电极表面 的光反射率, 增加光的吸收能力. 通过陷光结构的形貌 调控, 所制备的纳米钒酸铋光电极的光电流密度获得 了极大提升. 由IPCE与紫外-可见光光谱可知, 该光电 极性能的提升主要来自吸光能力的增强 ${ }^{[24]}$. 本课题 组 ${ }^{[39]}$ 通过对该光电极进一步优化, 在串联钙钛矿电池 后, 实现了约 $6.3 \%$ 的自供电太阳光制氢的效率(图3(c)).
相较于近年来电荷分离效率与催化产氧效率的高速发 展, $\mathrm{BiVO}_{4}$ 光阳极的吸光效率还存在很大的提升空间. 因此, 如何进一步提升光阳极的吸光效率, 是未来 $\mathrm{BiVO}_{4}$ 光阳极发展的关键.

\section{2 光生载流子分离效率}

对于 $\mathrm{BiVO}_{4}$ 光阳极, 将其所吸收的光子转化为光生 载流子是实现光电转换的第一步. 然而, 光生载流子的 分离效率 $\left(\Phi_{\mathrm{Sep}}\right)$ 目前还较低, 成为制约 $\mathrm{BiVO}_{4}$ 光阳极发 展的关键科学问题 ${ }^{[40]}$. 一般认为, 造成光生载流子分离 效率较低的原因主要是光生电子在 $\mathrm{BiVO}_{4}$ 内部传输时 与光生空穴复合. 因此, 降低 $\mathrm{BiVO}_{4}$ 在体相传输过程中 的损耗是提升 $\mathrm{BiVO}_{4}$ 光生载流子分离效率的关键 ${ }^{[40-42]}$. 采用含有如 $\mathrm{H}_{2} \mathrm{O}_{2}$ 或 $\mathrm{Na}_{2} \mathrm{SO}_{3}$ 等易被光生空穴氧化的空穴 捕获剂的电解液时, 由于电极表面产生的光生空穴极 易与电解液内的 $\mathrm{HO}_{2}{ }^{-}$或 $\mathrm{SO}_{3}{ }^{2-}$ 反应, 而基本不与电解液 中的 $\mathrm{OH}^{-}$发生反应，其催化产氧效率 $\left(\Phi_{\mathrm{OX}}\right)$ 或称为表面 分离效率 $\left(\eta_{\text {trans }}\right)$ 通常可以达到 $\approx 100 \%{ }^{[8,13,21,23]}$. 结合式 (1), 可通过用此电解液测试获得的光电流密度 $\left(J_{\mathrm{HS}}\right)$ 与 $J_{\text {abs }}$ 计算在各个电压下的 $\Phi_{\mathrm{Sep}}{ }^{[8,13,21]}$ :

$\Phi_{\mathrm{Sep}}=J_{\mathrm{HS}} / J_{\mathrm{abs}} \times 100 \%$.

本节将从纳米结构与晶面调控、缺陷态与异质结 构建 3 个方面介绍提升 $\mathrm{BiVO}_{4}$ 光阳极光生载流子分离效 率的方法.

\section{1 通过纳米结构与晶面调控增强光生载流子的分 离效率}

针对光生载流子在传输过程中存在较为严重复合 的问题, 构建纳米结构, 缩短传输时所需要的距离、减 少载流子复合的损耗是重要手段之一 ${ }^{[13,38]}$. Kim与 $\mathrm{Choi}^{\left[{ }^{[13]}\right.}$ 报道了一种具有纳米镂空结构的 $\mathrm{BiVO}_{4}$ 光阳极, 其制备方法为首先合成碘氧化铋 (BiOI)纳米片, 然后将 该电极在乙酰丙酮氧钒 $\left(\mathrm{VO}(\mathrm{acac})_{2}\right)$ 的浸渍下进行炦烧. 相较于偏钒酸铵为钒源制备的 $\mathrm{BiVO}_{4}$ 电极, 通过 $\mathrm{VO}(\mathrm{acac})_{2}$ 合成的 $\mathrm{BiVO}_{4}$ 光阳极在保留了一定 $\mathrm{BiOI}$ 纳米 片的形貌与镂空结构的同时, 缩小了 $\mathrm{BiVO}_{4}$ 颗粒的直 径, 有效地降低了光生电子与空穴的传输距离. 该电极 结合 $\mathrm{NiOOH} / \mathrm{FeOOH}$ 助催化剂后, 在 $1.23 \mathrm{~V}$ vs. RHE的 偏压下达到了 $4.5 \mathrm{~mA} \mathrm{~cm}{ }^{-2}$ 的光电流密度, 且 $\Phi_{\mathrm{Sep}}$ 在该 偏压下达到了接近 $100 \%{ }^{[13]}$. 此外, 钒酸铋具有晶体对 称性低而导致各向异性的特点使得不同晶面具有不同 
的电荷传输能力，因而可以被用来优化 $\mathrm{BiVO}_{4}$ 光阳 极 ${ }^{[40,43]}$. Han 等人 ${ }^{[43]}$ 通过控制晶面生长取向, 制备出优 先暴露 $[001]$ 晶面的 $\mathrm{BiVO}_{4}$ 光阳极. 由于 $[001]$ 面具有较 高的电荷传输能力, 相比无晶面取向的 $\mathrm{BiVO}_{4}$ 电极, 该 电极的 $\Phi_{\mathrm{Sep}}$ 从 $26 \%$ 大幅度提升至 $71 \%$. 并且, 在Co-Pi助 催化剂修饰后, 其在1.23 V vs. RHE偏压下的光电流密

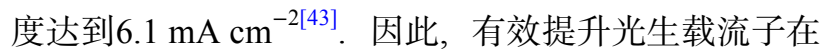
$\mathrm{BiVO}_{4}$ 内部传输时的效率, 减少在内部传输时光生电荷 的复合, 是提升 $\mathrm{BiVO}_{4}$ 光阳极性能的关键.

\section{2 通过掺杂缺陷态提升光生载流子分离效率}

由于光生载流子的复合主要由其在电极体相内传 输过程中复合所导致，有别于构建纳米形貌与晶面调 控的另一种提升光生载流子分离效率的主要手段是通 过引人缺陷态改变 $\mathrm{BiVO}_{4}$ 的电子结构, 从而提高电极的 电导率. 这种电导率的提升直接促进了 $\mathrm{BiVO}_{4}$ 内部载流 子的分离与传输. 其中, 以 $\mathrm{W}^{6+}$ 和 $\mathrm{Mo}^{6+}$ 单独或共掺杂取 代 $\mathrm{BiVO}_{4}$ 中的 $\mathrm{V}^{5+}$, 可提供更高的载流子浓度而提升 $\mathrm{BiVO}_{4}$ 性能 ${ }^{[44 ~ 47]}$. 近期, Pasumarthi等人 ${ }^{[44]}$ 通过第一性 原理方法计算了单组载流子的传输路径与跃迁活化能, 并结合介观尺度动力学蒙特卡罗方法模拟了大量载流 子的传输行为. 研究发现, $\mathrm{W}^{6+}$ 与 $\mathrm{Mo}^{6+}$ 共掺杂时, 尽管载 流子迁移率下降，但整体载流子浓度的提升导致整个
体相载流子传输能力增强, 为 $\mathrm{BiVO}_{4}$ 掺杂体系提供了提 升载流子传输能力的理论基础 ${ }^{[4]}$. 另一方面, 氧空位缺 陷的引人, 除了增加吸光能力之外, 也能提高 $\mathrm{BiVO}_{4}$ 光 阳极的载流子浓度从而提升光生载流子分离效率, 这 是其性能提升的另一因素. Wang等人 ${ }^{[48]}$ 利用新型硫氧 化法对 $\mathrm{BiVO}_{4}$ 光阳极的前驱体硫化铋 $\left(\mathrm{Bi}_{2} \mathrm{~S}_{3}\right)$ 进行处理, 在烧结的过程中原位生成带有氧空位缺陷的 $\mathrm{BiVO}_{4}$ 光 阳极(图4(a)). 该光阳极具有更长的光生载流子寿命(图 $4(\mathrm{~b}))$, 相应地获得了 $98.2 \%$ 的 $\Phi_{\mathrm{Sep}}{ }^{[48]}$. 但是, 由于氧空位 具有束缚极化子这一潜在问题，过多的氧空位缺陷反 而会负面影响 $\Phi_{\mathrm{Sep}}{ }^{[49]}$. Qiu等人 ${ }^{[49]}$ 利用一种高氧化性的 前驱体碘酸铋 $\left(\mathrm{BiOIO}_{3}\right)$ 作为内氧化剂, 开发了一条合成 $\mathrm{W}$ 掺杂 $\mathrm{BiVO}_{4}$ 光阳极的新途径. 随着氧空位缺陷的减 少，被束缚的极化子被释放，使得 $\mathrm{W}: \mathrm{BiVO}_{4}$ 内部的电荷 传输能力增强, 提升了电子与空穴的分离效率. 因此, 需要考虑引入缺陷态导致 $\mathrm{BiVO}_{4}$ 光阳极如能级、带 隙、表面态等多方面的变化, 以确保在尽可能地保留 $\mathrm{BiVO}_{4}$ 原本所具有的优势同时, 改进载流子分离效率.

\section{3 通过形成异质结复合光电极提升光生载流子分 离效率}

除了提升光生载流子在 $\mathrm{BiVO}_{4}$ 内部的传输性能外, 通过 $\mathrm{BiVO}_{4}$ 与其他能带匹配的半导体复合形成异质结 (a)

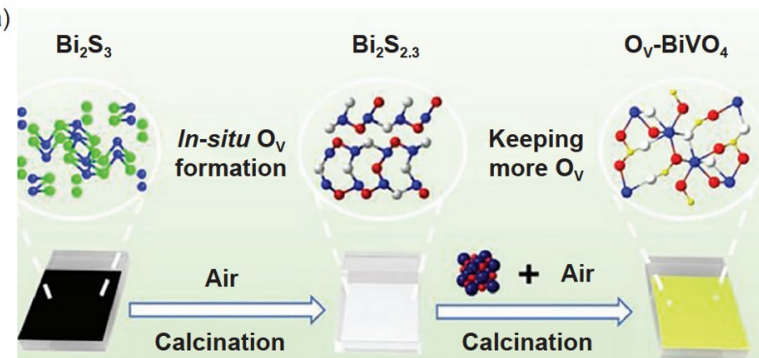

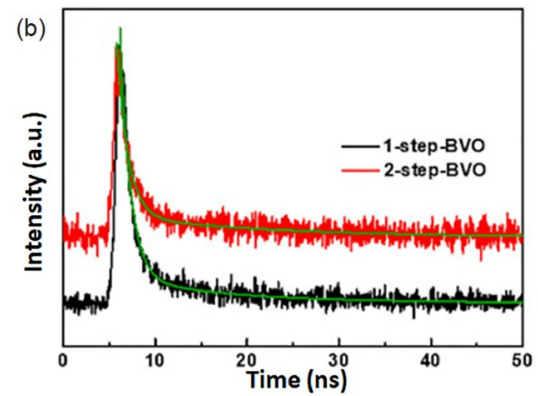
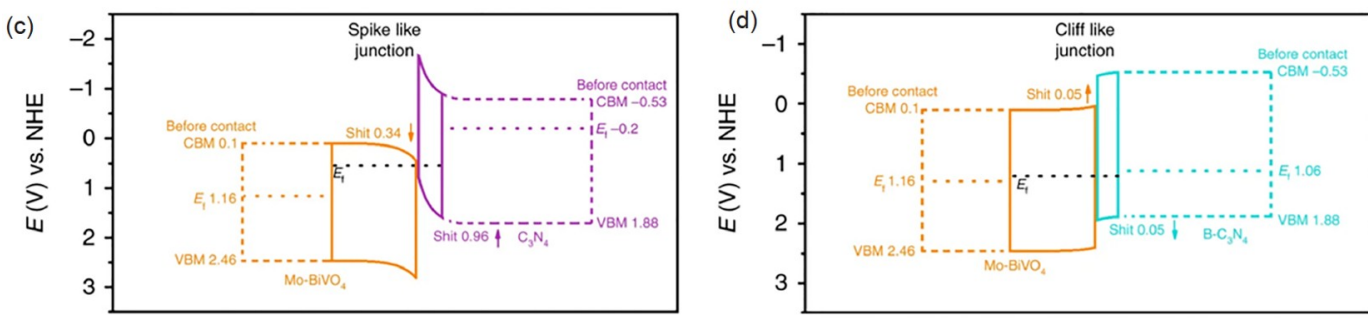

图 4 (网络版彩色)钒酸铋光阳极的光生载流子分离效率提升. (a) 两步法合成的 $\mathrm{BiVO}_{4}$ 光阳极示意图 ${ }^{[48]}$. (b) 一步法与两步法 $\mathrm{BiVO}_{4}$ 光阳极的时 间分辨苂光光谱 ${ }^{[48]} \cdot \mathrm{C}_{3} \mathrm{~N}_{4} / \mathrm{Mo}-\mathrm{BiVO}_{4}(\mathrm{c})$ 与 $\mathrm{B}-\mathrm{C}_{3} \mathrm{~N}_{4} / \mathrm{Mo}-\mathrm{BiVO}_{4}(\mathrm{~d})$ 异质结能带结构示意图 ${ }^{[55]}$

Figure 4 (Color online) Enhancement of photo-generated carrier separation efficiency of $\mathrm{BiVO}_{4}$ photoanode. (a) Schematic diagram showing the preparation of $\mathrm{BiVO}_{4}$ photoanode via a two-step process ${ }^{[48]}$. (b) Fluorescence emission time profiles of one-step $\mathrm{BiVO}_{4}$ and two-step $\mathrm{BiVO}_{4}$ photoanodes ${ }^{[48]}$. Schematic diagrams of the band structures of $\mathrm{C}_{3} \mathrm{~N}_{4} / \mathrm{Mo}-\mathrm{BiVO}_{4}(\mathrm{c})$ and $\mathrm{B}-\mathrm{C}_{3} \mathrm{~N}_{4} / \mathrm{Mo}^{-} \mathrm{BiVO}_{4}(\mathrm{~d})$ heterojunctions ${ }^{[55]}$ 
所产生的内建电场也是提升光生载流子分离效率的有 效手段 ${ }^{[50 \sim 53]}$. 这种有效手段被科学界广泛关注, 其中以 如 $\mathrm{WO}_{3} / \mathrm{BiVO}_{4}$ 这类由两个 $\mathrm{n}$ 型半导体组成的 $n-n$ 型异质 结为主 ${ }^{[23,25,30,38,51]}$. 但随着对 $\mathrm{BiVO}_{4}$ 研究的深人, 由于 $p-n$ 结具有特有的内建电场特性, 选择合适的 $p$ 型半导 体与 $\mathrm{BiVO}_{4}$ 构建 $\mathrm{p}-\mathrm{n}$ 型异质结以增强光生载流子的分离 获得了较大突破 ${ }^{[19,29,50,54]}$. 例如, Chang 等人 ${ }^{[54]}$ 通过 $p$ 型 $\mathrm{Co}_{3} \mathrm{O}_{4}$ 与 $\mathrm{n}$ 型 $\mathrm{BiVO}_{4}$ 的复合形成异质结, 其 $\mathrm{p}-\mathrm{n}$ 结的内建 电场使 $\mathrm{BiVO}_{4}$ 光阳极在 $1.23 \mathrm{~V}$ vs. RHE下的光生载流子 分离效率从 $56 \%$ 跃升至 $77 \%$. 与此同时, 在 $\mathrm{Co}_{3} \mathrm{O}_{4} / \mathrm{BiVO}_{4}$ $\mathrm{p}-\mathrm{n}$ 型异质结光阳极中, 由于 $\mathrm{Co}_{3} \mathrm{O}_{4}$ 可同时作为产氧助 催化剂, 光生空穴在 $\mathrm{p}-\mathrm{n}$ 结的作用下从 $\mathrm{BiVO}_{4}$ 传输至 $\mathrm{Co}_{3} \mathrm{O}_{4}$, 将 $\mathrm{BiVO}_{4}$ 在 $1.23 \mathrm{~V}$ vs. RHE下的催化产氧效率 从 $16 \%$ 猛升至 $47 \%^{[54]}$. 另一方面, $\mathrm{Ye}$ 等人 ${ }^{[55]}$ 复合 $\mathrm{Mo}-\mathrm{BiVO}_{4}$ 与 $\mathrm{C}_{3} \mathrm{~N}_{4}$ 形成异质结时发现, 因 $\mathrm{C}_{3} \mathrm{~N}_{4}$ 与 $\mathrm{Mo}-\mathrm{BiVO}_{4}$ 的能带与费米能级不匹配，会使其两者之间的界面形 成一个光生载流子复合中心(图4(c)). 为解决这一问题, 我们对 $\mathrm{C}_{3} \mathrm{~N}_{4}$ 进行了 $\mathrm{B}$ 的掺杂从而改变了其费米能级, 并 将其与 $\mathrm{Mo}-\mathrm{BiVO}_{4}$ 复合之后形成B- $\mathrm{C}_{3} \mathrm{~N}_{4} / \mathrm{Mo}-\mathrm{BiVO}_{4}$ 异质 结. 该异质结由于费米能级的调控, 使原本为光生载流 子复合中心的问题得到解决的同时, 反而能进一步地 增强分离载流子的能力 (图4(d) $)^{[55]}$. 在较低的偏压下 ( $0.6 \mathrm{~V}$ vs. RHE), 相较于Mo- $\mathrm{BiVO}_{4}, \mathrm{~B}-\mathrm{C}_{3} \mathrm{~N}_{4} / \mathrm{Mo}-\mathrm{BiVO}_{4}$ 异质结的 $\Phi_{\mathrm{Sep}}$ 得到了很大的提升, 达到了 $79 \%{ }^{[55]}$. 一般 $\mathrm{BiVO}_{4}$ 光阳极的载流子分离效率在高电压下均能获得 较高的水平, 而B- $\mathrm{C}_{3} \mathrm{~N}_{4} / \mathrm{Mo}-\mathrm{BiVO}_{4}$ 异质结在较低的偏压 下就能取得较高的光生载流子分离效率. 将光电分离 效率与更低偏压相结合将成为未来光电极发展的一个 方向 ${ }^{[55]}$.

\section{3 催化产氧效率}

$\mathrm{BiVO}_{4}$ 光阳极通过吸光过程和光电转化过程产生 的空穴在其表面附近聚集, 与从电解液中吸附到光电 极表面的 $\mathrm{OH}^{-}$反应生成 $\mathrm{H}_{2} \mathrm{O}$ 和 $\mathrm{O}_{2}$. 如上所述, 在含有如 $\mathrm{H}_{2} \mathrm{O}_{2}$ 或 $\mathrm{Na}_{2} \mathrm{O}_{3}$ 等空穴捕获剂的电解液内, 电极表面产氧 效率 $\left(\Phi_{\mathrm{OX}}\right)$ 可以达到 $\approx 100 \%{ }^{[8]}$. 因此, $\Phi_{\mathrm{OX}}$ 可通过测量在 电解液内没有任何空穴捕获剂时的光电流密度 $\left(J_{\mathrm{PEC}}\right)$ 和 在电解液内加人空穴捕获剂时 $\left(\Phi_{\mathrm{OX}} \approx 100 \%\right)$ 的光电流 密度 $\left(J_{\mathrm{HS}}\right)$ 得到:

$\Phi_{\mathrm{OX}} \approx J_{\mathrm{PEC}} / J_{\mathrm{HS}} \times 100 \%$.

由于一般情况下 $\mathrm{BiVO}_{4}$ 表面氧化产氧分解水动力
学性能低下, 光生空穴即使顺利到达表面也基本上不 能参与催化产氧反应, 而是与所遇到的光生电子复合, 严重降低了 $\Phi_{\mathrm{OX}}$, 在低电压区间 $(0.2 \sim 0.6 \mathrm{~V}$ vs. RHE)通 常不到 $10 \%{ }^{[21]}$. 目前尝试过的解决这一问题的主要手 段是在 $\mathrm{BiVO}_{4}$ 光阳极表面负载助催化剂或对表面进行 处理, 从而加快 $\mathrm{BiVO}_{4}$ 光阳极表面的OER动力学, 即提 升 $\Phi_{\mathrm{OX}}{ }^{[56,57]}$. 这些手段使得 $\mathrm{BiVO}_{4}$ 光阳极能够在没有空 穴捕获剂的真实反应条件下，充分发挥其光电转化效 率高的优势.

\section{1 通过负载助催化剂提升催化产氧效率}

光生空穴传输至 $\mathrm{BiVO}_{4}$ 表面时, 由于 $\mathrm{BiVO}_{4}$ 表面产 氧动力学能力较差, 空穴并不能有效地参与 OER反应. 因此, 通过负载有利于 OER分解水的助催化剂是提高 $\mathrm{BiVO}_{4}$ 光阳极 $\Phi_{\mathrm{OX}}$ 的直接手段. 该类助催化剂中较有潜 力的主要有 $\mathrm{Co}-\mathrm{Pi} 、 \mathrm{FeNi}-\mathrm{LDH}$ 等, 通过光电沉积, 可将 其优先沉积至 $\mathrm{BiVO}_{4}$ 光阳极的活性位点上 ${ }^{[57 ~ 59]}$. 但相较 于电催化分解水反应, $\mathrm{PEC}$ 分解水反应系统的设计, 除 了需要首先考虑OER性能外, 还需要考虑选用的助催 化剂与 $\mathrm{BiVO}_{4}$ 光阳极复合后是否会影响 $\mathrm{BiVO}_{4}$ 的吸光 能力或光生电子空穴对的分离能力等因素. Kim和 $\mathrm{Choi}^{[13]}$ 先在 $\mathrm{BiVO}_{4}$ 光阳极表面合成一层只传输空穴的 $\mathrm{FeOOH}$ 助催化剂, 光照时光生空穴源源不断地传输进 助 $\mathrm{FeOOH}$ 层, 有效地与光生电子隔绝, 减少了 $\mathrm{BiVO}_{4}$ 光 阳极的光生电子空穴对复合. 但是, 由于助 $\mathrm{FeOOH}$ 催化 剂层性能包括活性和稳定性都有很大的提升空间, 有 必要再在 $\mathrm{FeOOH} / \mathrm{BiVO}_{4}$ 表面沉积一层具有优异催化产 氧性能的 $\mathrm{NiOOH}$, 作为进一步增强OER性能和降低起 始电位的改进手段 ${ }^{[13]}$. 相较于直接使用 $\mathrm{NiOOH}$ 作为助 催化剂的 $\mathrm{NiOOH} / \mathrm{BiVO}_{4}, \mathrm{NiOOH} / \mathrm{FeOOH} / \mathrm{BiVO}_{4}$ 在保 持 $\mathrm{BiVO}_{4}$ 较高光电转化效率的同时, 获得了极低的起始 电位(接近 $\mathrm{BiVO}_{4}$ 在空穴捕获剂下测试的结果 $)^{[13]}$. 直接 使用 $\mathrm{NiOOH}$ 作为助催化层的 $\mathrm{NiOOH} / \mathrm{BiVO}_{4}$, 虽然有较 低的起始电位, 但由于缺乏空穴富集层引起的电子空 穴对复合等问题，其光电流密度衰减明显 ${ }^{[13]}$. 但是, $\mathrm{NiOOH} / \mathrm{FeOOH}$ 作为一种双层电催化剂, 本身合成步骤 较多而限制了其应用. 因此, 找到一种合成简易、成本 低廉的助催化剂成为 $\mathrm{BiVO}_{4}$ 光阳极研究的迫切需求. $\mathrm{NiFeO}_{x}$ 作为助催化剂目前被广泛应用于 $\mathrm{BiVO}_{4}$ 与其他 光阳极的研究中, 其不仅催化性能接近 $\mathrm{NiOOH} /$ $\mathrm{FeOOH}$, 而且具有合成步骤简单、成功率较高等优 点 ${ }^{[55]}$. 类似的助催化剂还有 $\mathrm{FeCoO} x$. Wang等人 ${ }^{[60]}$ 通过 
对 $\mathrm{CoO}_{x}$ 引人 $\mathrm{Fe}$ 掺杂, 在 $\mathrm{BiVO}_{4}$ 表面合成含有氧空位缺 陷的 $\mathrm{FeCoO}_{x}$ 助催化剂层(图 5(a)). 从 $\mathrm{FeCoO}_{x} / \mathrm{BiVO}_{4}$ 与 $\mathrm{CoO}_{x} / \mathrm{BiVO}_{4}$ 电极的计时电流曲线可知, 在 $10 \mathrm{~h}$ 的连续 反应下，性能未发现明显衰减(图5(b) $)^{[60]}$. 并且, 由于 $\mathrm{FeCoO}_{x}$ 为 $\mathrm{p}$ 型半导体, 与 $\mathrm{BiVO}_{4}$ 形成p-n结后, 有效地促 进了光生电子空穴对的分离、传输与表面产氧催化. 其 $\Phi_{\mathrm{OX}}$ 在 $1.23 \mathrm{~V}$ vs. RHE下达到了约 $90 \%$ (图5(c) $)^{[60]}$.

\section{2 通过表面修饰提升催化产氧效率}

表面处理 $\mathrm{BiVO}_{4}$ 光阳极是另一种廉价、简易的改 进性能的措施. 若能将性能进一步发展, 相较于负载助 催化剂, 对 $\mathrm{BiVO}_{4}$ 光阳极进行表面处理以改进光电转换 性能应该更适用于PEC在未来的规模化应用. 近期, Meng等人 ${ }^{[61]}$ 报道了对 $\mathrm{BiVO}_{4}$ 光阳极进行简易的嗍酸盐 缓冲液处理的结果(图5(d)). 通过在分子水平引入硼的 修饰, 增加了 $\mathrm{BiVO}_{4}$ 表面催化产氧活性位点, 提升了 $\mathrm{BiVO}_{4}$ 的产氧效率, 使其起始电位提前了 $250 \mathrm{mV}$, 并在 没有其他助催化剂的前提下, 在 $1.23 \mathrm{~V}$ vs. RHE偏压下 光电流密度达到了 $3.5 \mathrm{~mA} \mathrm{~cm}^{-2}$ (图5(e) $)^{[61]}$. 另一方面, Gao和Wang ${ }^{[56]}$ 利用恒电位光极化法在 $\mathrm{BiVO}_{4}$ 表面原位 引人大量的氧空位缺陷, 在电极使用过程中, 电解液或
空气中的氧又重新填补上该氧缺陷，获得了一种非晶 态的 $\mathrm{BiVO}_{4}$ 表面针化层. 这种非晶态的表面钝化层使该 电极在没有使用助催化剂的前提下，起始电位达到了 $0.23 \mathrm{~V}$ vs. RHE, 并在 $1.23 \mathrm{~V}$ vs. RHE的偏压下, 光电流 密度达到了 $4.6 \mathrm{~mA} \mathrm{~cm}^{-2[56]}$. 同时, 这种引人表面氧空位 缺陷与重新钝化的方法还提供了很强的“自愈”性，拥 有超过 $100 \mathrm{~h}$ 的光稳定性, 对今后 $\mathrm{BiVO}_{4}$ 光阳极的成本 降低乃至大面积应用具有指导意义 ${ }^{[56]}$.

\section{4 总结与展望}

随着 $\mathrm{BiVO}_{4}$ 作为典型的光阳极被科学界广泛研究, 目前世界范围内所制备的高性能 $\mathrm{BiVO}_{4}$ 光电极在高电 压(1.23 V vs. RHE)下的光电流密度已达到较高水平, 尤其是许多见诸报道的 $\Phi_{\mathrm{Sep}}$ 与 $\Phi_{\mathrm{OX}}$ 均已突破 $90 \%$ ，稳定 性也相当出色. 这些可喜的进展来自对 $\mathrm{BiVO}_{4}$ 光电极的 光电化学水分解等基础科学问题的深人研究. 但是, 由 于 $\mathrm{BiVO}_{4}$ 光电极在低电压区间 $(0.2 \sim 0.6 \mathrm{~V}$ vs. RHE)的光 电流密度仍然较低, 导致ABPE仍然较低(1\% 2.5\%), 因 此, 距离PEC分解水的规模化应用仍然较远, 巨大的潜 力仍然有待被开发. 展望未来, 进一步提升 $\mathrm{BiVO}_{4}$ 光电 极的PEC分解水能力可以聚焦于以下 3 个方面: (1) 改进 (a)

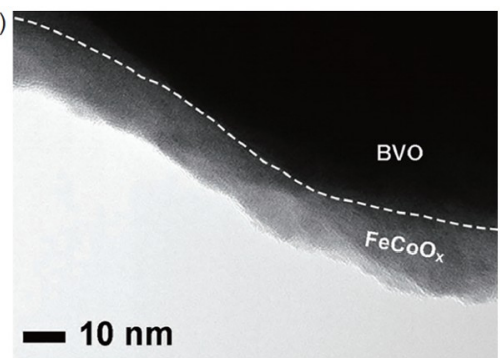

(d)

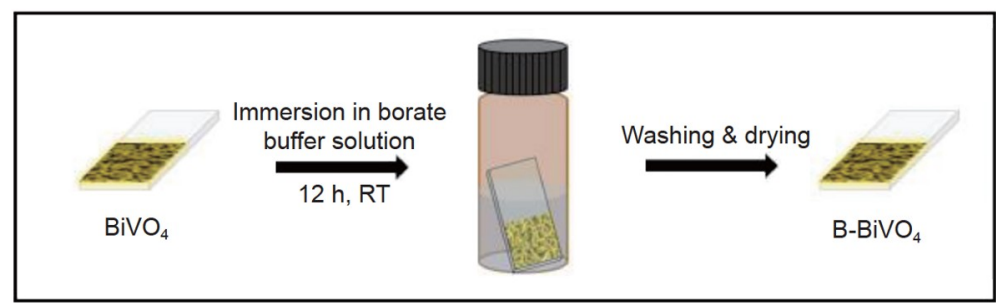

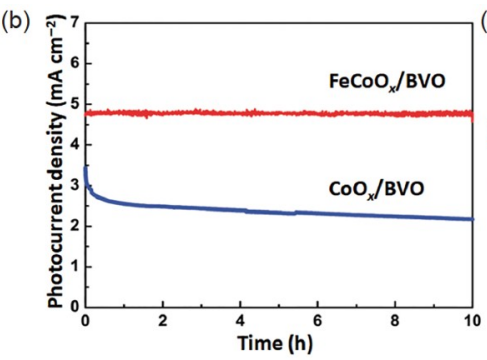
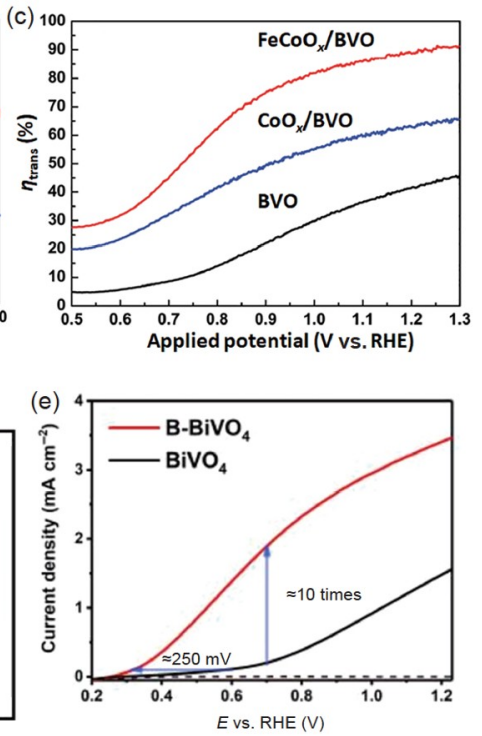

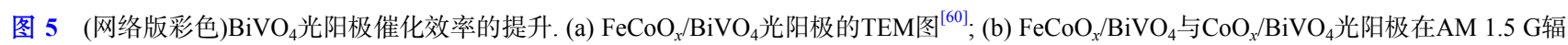
射下与 $1.23 \mathrm{~V}$ vs. RHE偏压下的计时光电流密度曲线 ${ }^{[60]}$; (c) $\mathrm{FeCoO}_{x} / \mathrm{BiVO}_{4} 、 \mathrm{CoO}_{x} / \mathrm{BiVO}_{4}$ 与 $\mathrm{BiVO}_{4}$ 光阳极的催化效率与外加电压曲线 ${ }^{[60]}$; (d) B$\mathrm{BiVO}_{4}$ 光阳极示意图 ${ }^{[61]} ;(\mathrm{e}) \mathrm{B}-\mathrm{BiVO}_{4}$ 与 $\mathrm{BiVO}_{4}$ 光阳极的 $J-V$ 曲线 ${ }^{[61]}$

Figure 5 (Color online) Enhancement of catalytic efficiency of $\mathrm{BiVO}_{4}$ photoanode. (a) TEM image of the $\mathrm{FeCoO}_{x} / \mathrm{BiVO}_{4}$ photoanode ${ }^{[60]}$; (b) time dependent photocurrent density curves at $1.23 \mathrm{~V}$ versus RHE under $\mathrm{AM} 1.5 \mathrm{G}$ illumination of the $\mathrm{FeCoO}_{x} / \mathrm{BiVO}_{4}$ and $\mathrm{CoO}_{x} / \mathrm{BiVO}_{4}$ photoanodes ${ }^{[60]}$; (c) catalytic efficiency versus applied potential curves of the $\mathrm{FeCoO}_{x} / \mathrm{BiVO}_{4}, \mathrm{CoO}_{x} / \mathrm{BiVO}_{4}$ and $\mathrm{BiVO}_{4}$ photoanodes ${ }^{[60]}$; (d) schematic diagram showing the B-BiVO 4 photoanode preparation ${ }^{[61]}$; (e) $J-V$ curves of $\mathrm{BiVO}_{4}$ and $\mathrm{B}-\mathrm{BiVO}_{4}$ photoanodes ${ }^{[61]}$ 
$\mathrm{BiVO}_{4}$ 光电极, 使其拥有更强的吸光能力与更宽的吸光 范围, 从而提高LHE和 $J_{\mathrm{abs}}$; (2) 通过材料和结构设计, 努 力在更低的偏压下达到更高的 $\Phi_{\mathrm{Sep}}$ 与 $\Phi_{\mathrm{OX}}$, 从而使 $\mathrm{ABPE}$ 获得总体提升; (3) 通过合理设计构建以 $\mathrm{BiVO}_{4}$ 光电极为主体的高性能光电化学分解水器件, 包括串 联光阴极或太阳能电池形成分解水反应器, 从而摆脱 对外接电压的依赖. 随着量子点、纳米线、二维材 料、金属有机框架材料、卤化钙钛矿材料、单原子催
化剂等在光子学、光电子学、材料学等领域展现出来 的无限可能性 ${ }^{[62 ~ 67]}$, 其巧妙应用于 $\mathrm{BiVO}_{4}$ 光电极将会进 一步释放 $\mathrm{BiVO}_{4}$ 光电极的潜力. 当然, $\mathrm{BiVO}_{4}$ 光电极不 一定是最终的PEC大规模应用方案, 新的光电极探索 会在相当一段时间内一直在路上. 无论如何, 基于研究 $\mathrm{BiVO}_{4}$ 光电极典型的实践、结论及其上升和推广, 将会 为下一代革命性的清洁能源所需要的光电化学电极的 开拓指明方向.

\section{参考文献}

1 Grätzel M. Photoelectrochemical cells. Nature, 2001, 414: 338-344

2 Sivula K, van de Krol R. Semiconducting materials for photoelectrochemical energy conversion. Nat Rev Mater, 2016, 1: 15010

3 Moniz S J A, Shevlin S A, Martin D J, et al. Visible-light driven heterojunction photocatalysts for water splitting-A critical review. Energy Environ Sci, 2015, 8: 731-759

4 Fan W, Zhang B, Wang X, et al. Efficient hydrogen peroxide synthesis by metal-free polyterthiophene via photoelectrocatalytic dioxygen reduction. Energy Environ Sci, 2020, 13: 238-245

5 Gan J, Lu X, Tong Y. Towards highly efficient photoanodes: Boosting sunlight-driven semiconductor nanomaterials for water oxidation. Nanoscale, 2014, 6: 7142-7164

6 Lu X, Xie S, Yang H, et al. Photoelectrochemical hydrogen production from biomass derivatives and water. Chem Soc Rev, 2014, 43: 7581-7593

7 Shi X, Choi I Y, Zhang K, et al. Efficient photoelectrochemical hydrogen production from bismuth vanadate-decorated tungsten trioxide helix nanostructures. Nat Commun, 2014, 5: 4775

8 Abdi F F, Han L, Smets A H M, et al. Efficient solar water splitting by enhanced charge separation in a bismuth vanadate-silicon tandem photoelectrode. Nat Commun, 2013, 4: 2195

9 Takata T, Jiang J, Sakata Y, et al. Photocatalytic water splitting with a quantum efficiency of almost unity. Nature, 2020, 581: 411-414

10 Wang H, Xia Y, Li H, et al. Highly active deficient ternary sulfide photoanode for photoelectrochemical water splitting. Nat Commun, 2020, 11: 3078

11 Abdi F F, Berglund S P. Recent developments in complex metal oxide photoelectrodes. J Phys D-Appl Phys, 2017, 50: 193002

12 Tolod K, Hernández S, Russo N. Recent advances in the $\mathrm{BiVO}_{4}$ photocatalyst for sun-driven water oxidation: Top-performing photoanodes and scale-up challenges. Catalysts, 2017, 7: 13

13 Kim T W, Choi K S. Nanoporous BiVO 4 photoanodes with dual-layer oxygen evolution catalysts for solar water splitting. Science, 2014, 343: 990994

14 L Formal F, Tétreault N, Cornuz M, et al. Passivating surface states on water splitting hematite photoanodes with alumina overlayers. Chem Sci, 2011, 2: 737-743

15 Park Y, McDonald K J, Choi K S. Progress in bismuth vanadate photoanodes for use in solar water oxidation. Chem Soc Rev, 2013, 42: 2321-2337

16 Luo W, Yang Z, Li Z, et al. Solar hydrogen generation from seawater with a modified BiVO 4 photoanode. Energy Environ Sci, 2011, 4: 4046-4051

17 Qiu W, Huang Y, Tang S, et al. Thin-layer indium oxide and cobalt oxyhydroxide cobalt-modified BiVO ${ }_{4}$ photoanode for solar-assisted water electrolysis. J Phys Chem C, 2017, 121: 17150-17159

18 Kuang Y, Jia Q, Nishiyama $\mathrm{H}$, et al. A front-illuminated nanostructured transparent $\mathrm{BiVO}_{4}$ photoanode for $>2 \%$ efficient water splitting. Adv Energy Mater, 2016, 6: 1501645

19 Ye K H, Chai Z, Gu J, et al. BiOI-BiVO 4 photoanodes with significantly improved solar water splitting capability: p-n junction to expand solar adsorption range and facilitate charge carrier dynamics. Nano Energy, 2015, 18: 222-231

$20 \mathrm{Xu} \mathrm{H}$, Fan W, Zhao Y, et al. Amorphous iron (III)-borate decorated electrochemically treated-BiVO ${ }_{4}$ photoanode for efficient photoelectrochemical water splitting. Chem Eng J, 2021, 411: 128480

21 Ye K H, Wang Z, Gu J, et al. Carbon quantum dots as a visible light sensitizer to significantly increase the solar water splitting performance of bismuth vanadate photoanodes. Energy Environ Sci, 2017, 10: 772-779

22 Resasco J, Zhang H, Kornienko N, et al. $\mathrm{TiO}_{2} / \mathrm{BiVO}_{4}$ nanowire heterostructure photoanodes based on type II band alignment. ACS Cent Sci, 2016, 2: $80-88$

23 Rao P M, Cai L, Liu C, et al. Simultaneously efficient light absorption and charge separation in $\mathrm{WO}_{3} / \mathrm{BiVO}_{4}$ core/shell nanowire photoanode for 
photoelectrochemical water oxidation. Nano Lett, 2014, 14: 1099-1105

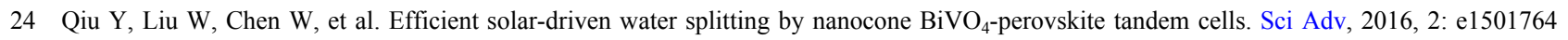

$25 \mathrm{Xu} \mathrm{S}, \mathrm{Fu} \mathrm{D}$, Song K, et al. One-dimensional $\mathrm{WO}_{3} / \mathrm{BiVO}_{4}$ heterojunction photoanodes for efficient photoelectrochemical water splitting. Chem Eng J, 2018, 349: 368-375

26 Zhao X, Hu J, Chen S, et al. An investigation on the role of $\mathrm{W}$ doping in $\mathrm{BiVO}_{4}$ photoanodes used for solar water splitting. Phys Chem Chem Phys, 2018, 9: 8860-8870

27 Zhong D K, Choi S, Gamelin D R. Near-complete suppression of surface recombination in solar photoelectrolysis by "Co-Pi” catalyst-modified W: BiVO $_{4}$. J Am Chem Soc, 2011, 133: 18370-18377

28 Zhong X, He H, Yang M, et al. $\mathrm{In}^{3+}$-doped $\mathrm{BiVO}_{4}$ photoanodes with passivated surface states for photoelectrochemical water oxidation. J Mater Chem A, 2018, 6: 10456-10465

29 Ye K H, Yu X, Qiu Z, et al. Facile synthesis of bismuth oxide/bismuth vanadate heterostructures for efficient photoelectrochemical cells. RSC Adv, 2015, 5: 34152-34156

30 Grigioni I, Stamplecoskie K G, Jara D H, et al. Wavelength-dependent ultrafast charge carrier separation in the $\mathrm{WO}_{3} / \mathrm{BiVO}_{4}$ coupled system. ACS Energy Lett, 2017, 2: 1362-1367

31 Wang G, Ling Y, Lu X, et al. Computational and photoelectrochemical study of hydrogenated bismuth vanadate. J Phys Chem C, 2013, 117: 10957-10964

32 Tian $\mathrm{Z}$, Zhang P, Qin P, et al. Novel black $\mathrm{BiVO}_{4} / \mathrm{TiO}_{2-x}$ photoanode with enhanced photon absorption and charge separation for efficient and stable solar water splitting. Adv Energy Mater, 2019, 9: 1901287

33 Kim T W, Ping Y, Galli G A, et al. Simultaneous enhancements in photon absorption and charge transport of bismuth vanadate photoanodes for solar water splitting. Nat Commun, 2015, 6: 8769

34 Tang D, Zhang H, Huang $\mathrm{H}$, et al. Carbon quantum dots enhance the photocatalytic performance of $\mathrm{BiVO}_{4}$ with different exposed facets. Dalton Trans, 2013, 42: 6285-6289

35 Nan F, Kang Z, Wang J, et al. Carbon quantum dots coated $\mathrm{BiVO}_{4}$ inverse opals for enhanced photoelectrochemical hydrogen generation. Appl Phys Lett, 2015, 106: 153901

36 Tang S, Qiu W, Xiao S, et al. Harnessing hierarchical architectures to trap light for efficient photoelectrochemical cells. Energy Environ Sci, 2020, 13: $660-684$

37 Qiu Y, Leung S F, Zhang Q, et al. Efficient photoelectrochemical water splitting with ultrathin films of hematite on three-dimensional nanophotonic structures. Nano Lett, 2014, 14: 2123-2129

38 Zhang $\mathrm{H}$, Zhou W, Yang Y, et al. 3D $\mathrm{WO}_{3} / \mathrm{BiVO}_{4} /$ cobalt phosphate composites inverse opal photoanode for efficient photoelectrochemical water splitting. Small, 2017, 13: 1603840

39 Xiao S, Hu C, Lin H, et al. Integration of inverse nanocone array based bismuth vanadate photoanodes and bandgap-tunable perovskite solar cells for efficient self-powered solar water splitting. J Mater Chem A, 2017, 5: 19091-19097

40 Li R, Zhang F, Wang D, et al. Spatial separation of photogenerated electrons and holes among $\{010\}$ and $\{110\}$ crystal facets of BiVO $\mathrm{Nat}_{4}$ Commun, 2013, 4: 1432

41 Xiao S, Chen H, Yang Z, et al. Origin of the different photoelectrochemical performance of mesoporous $\mathrm{BiVO}_{4}$ photoanodes between the $\mathrm{BiVO}_{4}$ and the FTO side illumination. J Phys Chem C, 2015, 119: 23350-23357

42 Huang M, Li C, Zhang L, et al. Twin structure in $\mathrm{BiVO}_{4}$ photoanodes boosting water oxidation performance through enhanced charge separation and transport. Adv Energy Mater, 2018, 8: 1802198

43 Han H S, Shin S, Kim D H, et al. Boosting the solar water oxidation performance of a $\mathrm{BiVO}_{4}$ photoanode by crystallographic orientation control. Energy Environ Sci, 2018, 11: 1427

44 Pasumarthi V, Liu T, Dupuis M, et al. Charge carrier transport dynamics in W/Mo-doped $\mathrm{BiVO}_{4}$ : First principles-based mesoscale characterization. J Mater Chem A, 2019, 7: 3054-3065

45 Xie S, Zhai T, Zhu Y, et al. NiO decorated $\mathrm{Mo}: \mathrm{BiVO}_{4}$ photoanode with enhanced visible-light photoelectrochemical activity. Int J Hydrog Energy, 2014, 39: 4820-4827

46 Lakey P S J, George I J, Baeza-Romero M T, et al. Organics substantially reduce $\mathrm{HO}_{2}$ uptake onto aerosols containing transition metal ions. J Phys Chem A, 2016, 120: 1421-1430

47 Zhao X, Hu J, Chen S, et al. An investigation on the role of $\mathrm{W}$ doping in $\mathrm{BiVO}_{4}$ photoanodes used for solar water splitting. Phys Chem Chem Phys, 2018, 20: 13637-13645

48 Wang $\mathrm{S}, \mathrm{He} \mathrm{T}$, Chen $\mathrm{P}$, et al. In situ formation of oxygen vacancies achieving near-complete charge separation in planar $\mathrm{BiVO}_{4}$ photoanodes. $\mathrm{Adv}$ Mater, 2020, 32: 2001385

49 Qiu W, Xiao S, Ke J, et al. Freeing the polarons to facilitate charge transport in $\mathrm{BiVO}_{4}$ from oxygen vacancies with an oxidative $2 \mathrm{D}$ precursor. 
Angew Chem Int Edit, 2019, 58: 19087-19095

50 Zhong M, Hisatomi T, Kuang Y, et al. Surface modification of $\mathrm{CoO}_{x}$ loaded $\mathrm{BiVO}_{4}$ photoanodes with ultrathin p-type NiO layers for improved solar water oxidation. J Am Chem Soc, 2015, 137: 5053-5060

$51 \mathrm{Su}$ J, Guo L, Bao N, et al. Nanostructured $\mathrm{WO}_{3} / \mathrm{BiVO}_{4}$ heterojunction films for efficient photoelectrochemical water splitting. Nano Lett, 2011, 11: 1928-1933

52 Li C, Wang S, Wang T, et al. Monoclinic porous $\mathrm{BiVO}_{4}$ networks decorated by discrete $\mathrm{g}_{-} \mathrm{C}_{3} \mathrm{~N}_{4}$ nano-islands with tunable coverage for highly efficient photocatalysis. Small, 2014, 10: 2783-2790

53 Zhang K, Jin B, Park C, et al. Black phosphorene as a hole extraction layer boosting solar water splitting of oxygen evolution catalysts. Nat Commun, 2019, 10: 2001

54 Chang X, Wang T, Zhang P, et al. Enhanced surface reaction kinetics and charge separation of p-n heterojunction $\mathrm{Co}_{3} \mathrm{O}_{4} / \mathrm{BiVO}_{4}$ photoanodes. $\mathrm{J}$ Am Chem Soc, 2015, 137: 8356-8359

55 Ye K H, Li H, Huang D, et al. Enhancing photoelectrochemical water splitting by combining work function tuning and heterojunction engineering. Nat Commun, 2019, 10: 3687

56 Gao R T, Wang L. Stable cocatalyst-free $\mathrm{BiVO}_{4}$ photoanodes with passivated surface states for photocorrosion inhibition. Angew Chem Int Edit, 2020, 59: 23094-23099

57 Ma Y, Kafizas A, Pendlebury S R, et al. Photoinduced absorption spectroscopy of CoPi on $\mathrm{BiVO}_{4}$ : The function of CoPi during water oxidation. Adv Funct Mater, 2016, 26: 4951-4960

58 Bai S, Chu H, Xiang X, et al. Fabricating of $\mathrm{Fe}_{2} \mathrm{O}_{3} / \mathrm{BiVO}_{4}$ heterojunction based photoanode modified with NiFe-LDH nanosheets for efficient solar water splitting. Chem Eng J, 2018, 350: 148-156

59 Wang Q, Niu T, Lei W, et al. NiFe layered double-hydroxide nanoparticles for efficiently enhancing performance of $\mathrm{BiVO}_{4}$ photoanode in photoelectrochemical water splitting. Chin J Catal, 2018, 39: 613-618

60 Wang S, He T, Yun J, et al. New iron-cobalt oxide catalysts promoting $\mathrm{BiVO}_{4}$ films for photoelectrochemical water splitting. Adv Funct Mater, 2018, 28: 1802685

61 Meng Q, Zhang B, Fan L, et al. Efficient $\mathrm{BiVO}_{4}$ photoanodes by postsynthetic treatment: Remarkable improvements in photoelectrochemical performance from facile borate modification. Angew Chem Int Edit, 2019, 58: 19027-19033

62 Zhou T, Chen S, Li L, et al. Carbon quantum dots modified anatase/rutile $\mathrm{TiO}_{2}$ photoanode with dramatically enhanced photoelectrochemical performance. Appl Catal B-Environ, 2020, 269: 118776

63 Chen H M, Chen C K, Liu R S, et al. A new approach to solar hydrogen production: A ZnO-ZnS solid solution nanowire array photoanode. Adv Energy Mater, 2011, 1: 742-747

64 Zheng H, Lu Y, Ye K H, et al. Atomically thin photoanode of InSe/graphene heterostructure. Nat Commun, 2021, 12: 91

65 Yang H, Bright J, Kasani S, et al. Metal-organic framework coated titanium dioxide nanorod array p-n heterojunction photoanode for solar watersplitting. Nano Res, 2019, 12: 643-650

66 Rao H S, Li W G, Chen B X, et al. In situ growth of $120 \mathrm{~cm}^{2} \mathrm{CH}_{3} \mathrm{NH}_{3} \mathrm{PbBr}_{3}$ perovskite crystal film on FTO glass for narrowband-photodetectors. Adv Mater, 2017, 29: 1602639

67 Ramalingam V, Varadhan P, Fu H C, et al. Heteroatom-mediated interactions between ruthenium single atoms and an MXene support for efficient hydrogen evolution. Adv Mater, 2019, 31: 1903841 


\title{
Recent progress of bismuth vanadate-based photoelectrocatalytic water splitting
}

\author{
Kai-Hang Ye ${ }^{1,2}$, Tongxin Tang ${ }^{1}$, Zhiting Liang ${ }^{1}$, Hongbing $\mathrm{Ji}^{1,3}$, Zhan $\operatorname{Lin}^{1 *} \&$ Shihe Yang $^{2 *}$ \\ ${ }^{1}$ Guangzhou Key Laboratory of Clean Transportation Energy Chemistry, School of Chemical Engineering and Light Industry, Guangdong University of \\ Technology, Guangzhou 510006, China; \\ ${ }^{2}$ Guangdong Key Lab of Nano-Micro Material Research, School of Chemical Biology and Biotechnology, Shenzhen Graduate School, Peking \\ University, Shenzhen 518055, China; \\ ${ }^{3}$ Fine Chemical Industry Research Institute, School of Chemistry, Sun Yat-sen University, Guangzhou 510275, China \\ * Corresponding authors, E-mail: zhanlin@gdut.edu.cn; chsyang@pku.edu.cn
}

With increasing energy demands and ever-growing environmental concerns, solar energy and hydrogen energy have attracted worldwide attention. In particular, hydrogen energy not only has a high energy density, but also is clean, renewable, and carbon-free, when compared with primary energy sources such as coal, oil, and natural gas and secondary energy sources such as coal gas, petrol, and diesel. Photoelectrocatalytic (PEC) water splitting for hydrogen generation is a process in which a PEC cell containing photoelectrodes and electrolyte is used to split water into hydrogen and oxygen by solar energy. Therefore, PEC water splitting is one of the ideal ways to covert and store solar energy to hydrogen energy in terms of chemical bond energy. In a PEC cell, the photoanode is commonly based on n-type semiconductors and the photocathode based on p-type semiconductors. The efficiency of a PEC cell is determined by performance of these photoelectrodes interfaced with the electrolyte. However, because the oxygen evolution reaction on the photoanode is kinetically sluggish involving four electrons and the valance band maximum of photoanodes must be more positive than $1.23 \mathrm{~V}$ versus reversible hydrogen electrode, suitable $\mathrm{n}$-type semiconductors are quite few for this purpose, limiting the common photoanodes to low efficiencies for PEC water splitting. In recent years, the bismuth vanadate photoanode has attracted great attention due to its relatively high theoretical maximum photocurrent density $\left.(\approx 7 \mathrm{~mA} \mathrm{~cm})^{-2}\right)$ and suitable band structure for water splitting, compared with other traditional photoanodes such as titanium dioxide, tungsten oxide, and zinc oxide. Extensive efforts have been made to unleash the full potential of the bismuth vanadate photoanode for PEC water splitting. In this mini review, we survey and analyze the design ideas and synthesis methods of high-performance bismuth vanadate photoanodes by looking back at the research progress made over the past few years on improving the light harvesting efficiency, photo-generated carrier separation efficiency and surface oxygen evolution efficiency of bismuth vanadate photoanodes. The strategies for improving the efficiencies of the bismuth vanadate photoanodes include defect state introduction, crystal facet and morphology control, and heterojunction engineering. Among the strategies, a single one, such as the defect state introduction, may enhance efficiencies of several processes (e.g., photo-generated carrier separation efficiency and surface oxygen evolution efficiency) of bismuth vanadate at the same time, but sometimes, it may enhance the efficiency of one process but degrade the efficiencies of others for the bismuth vanadate photoanode. Thus, how to comprehensively consider the cooperative mechanism to enhance the efficiencies of all the processes involved in PEC water splitting is the key to obtaining high performance bismuth vanadate photoanodes. At present, bismuth vanadate-based photoanodes have exhibited an extremely high photocurrent density and photo-generated carrier separation efficiency at higher bias voltage (over $5 \mathrm{~mA} \mathrm{~cm}$ at $1.23 \mathrm{~V}$ versus reversible hydrogen electrode with over $90 \%$ photo-generated carrier separation efficiency), but the light reflection of bismuth vanadate-based photoanodes makes it unable to reach the theoretical maximum photocurrent density $(\approx 7 \mathrm{~mA} \mathrm{~cm})^{-2}$. Moreover, the efficiencies of bismuth vanadate-based photoanodes at low bias voltages are still too low. Therefore, the future development direction should be to obtain higher photocurrent density at a lower voltage, and increase the absorption efficiency and wavelength range of bismuth vanadate to reach the theoretical photocurrent density and beyond. Although bismuth vanadate photoanodes are not necessarily the final large-scale application scheme of PEC water splitting in the future, their studies will help to provide guidelines for searching new high-performance photoanode materials.

photoelectrocatalytic, water splitting, bismuth vanadate, photoanode

doi: 10.1360/TB-2021-0238 